\title{
Feminismo y perspectiva de género en la Paleontología
}

\author{
Luis J. ABEJEZ ${ }^{*}$ \& Cristina CORONA ${ }^{2}$
}

${ }^{1}$ Laboratorio de Patrimonio y Turismo Cultural, Universidad de Barcelona/Red IBERTUR; Centro de Estudios de Antropología de la Mujer(CEAM), México; abejez@gmail.com

${ }^{2}$ Subdirectora de Paleontología, Coordinación Nacional de Arqueología, Instituto Nacional de Antropología e Historia (INAH); Seminario Patrimonio Cultural: Antropología, Historia y Legislación, INAH, México; Centro de Estudios de Antropología de la Mujer (CEAM), México; cristinacoronaj@gmail.com

*Corresponding author

Abejez, L.J. \& Corona, C. 2020. Feminismo y perspectiva de género en la Paleontología. [Feminism and gender perspective in Palaeontology]. Spanish Journal of Palaeontology, 35 (1), 29-46.

Manuscript received 20 December 2018

Manuscript accepted 31 January 2019 https://doi.org/10.7203/sjp.35.1.17178

(C) Sociedad Española de Paleontología ISSN 2255-0550

\section{ABSTRACT}

Since the mid-twentieth century, feminist movements have focused much of their criticisms on the presence of androcentric biases in most scientific disciplines, causing in some of them a true revolution at a theoretical and practical level. This revolution has succeeded in their transformation in a substantial and meaningful way. During this time, palaeontology has remained relatively indifferent to these processes, perhaps because its seeming objectivity and the particular characteristics of its main object of study (the fossils) seem to isolate it from the influences coming from the current social thoughts. However, like any other science, palaeontology reflects the society in which it develops, and consequently, is also influenced, directly or indirectly, by a patriarchal ideology that continues active and discriminates against the feminine.

Throughout this article we will describe how this ideology and its associated biases have manifested themselves in this professional practice; in the expressions and in the language used in their interpretations; in the reproduction of stereotypes; and in the exhibition, communication and dissemination of knowledge resulting from their research, especially in museums. The ultimate goal of this paper is to propose a reflection based on constructive criticism

\section{RESUMEN}

Desde mediados del siglo XX, los movimientos feministas han centrado buena parte de sus críticas en la presencia de sesgos androcéntricos en la mayoría de las disciplinas científicas, lo que en algunas de ellas ha generado una auténtica revolución a nivel teórico y práctico que ha conseguido transformarlas de una forma sustancial y significativa. Durante este tiempo, la paleontología ha quedado relativamente al margen de este proceso, quizás porque su aparente objetividad y las particulares características de su principal objeto de estudio parecen aislarla de las influencias procedentes de las modernas corrientes de pensamiento social. No obstante, al igual que cualquier otra ciencia, la paleontología es un reflejo de la sociedad en la que se desarrolla. En consecuencia, también se encuentra influenciada, directa o indirectamente, por una ideología patriarcal que continúa presente y discrimina lo femenino en todos los ámbitos.

En este artículo se describen algunos ejemplos de cómo esta ideología y sus sesgos asociados se han manifestado en la práctica profesional y en la investigación paleontológica; en las expresiones y el lenguaje utilizados en sus interpretaciones; en la reproducción de estereotipos, y en la exposición y comunicación del conocimiento resultado de sus investigaciones, especialmente en los museos. El objetivo 
that allows incorporating a new perspective, which brings palaeontology closer to the reality of the 21 st century, where the role of women is increasingly recognized and scientific studies try to be inclusive and free from prejudice.

Keywords: Androcentric bias, dissemination, fossils, museums, science. es proponer una reflexión a partir de una crítica constructiva, la cual permita incorporar una nueva mirada que acerque la paleontología a la realidad del siglo XXI, donde el papel de la mujer es cada día más reconocido y los estudios científicos intentan ser inclusivos y libres de prejuicios.

Palabras clave: Sesgos androcéntricos, divulgación, fósiles, museos, ciencia.

"A menudo cometo la equivocación de pensar que algo que a mí me resulta obvio es igual de obvio para todo el mundo". Chimamanda Ngozi Adichie (2019). Todos deberíamos ser feministas.

\section{INTRODUCCIÓN}

En la década de 1960, diferentes movimientos sociales e intelectuales críticos frente al conservadurismo establecido irrumpieron en las universidades de Estados Unidos. Su espíritu contracultural se enfrentó a las concepciones científicas tradicionales, provocando cambios sustanciales en prácticamente todas las ciencias. La paleontología no se quedó al margen. En ese momento de cambio, de avances tecnológicos e importantes hallazgos, la incorporación de jóvenes investigadores e investigadoras introdujo nuevas inquietudes que revitalizaron la disciplina (Fastovsky, 2009; Fastovsky \& Weishampel, 2009) y dieron paso a la denominada Dinosaur renaissance. Principles of Paleontology (Raup \& Stanley, 1971) significó, en este sentido, un punto de inflexión, al centrarse más en cuestiones teóricas, como la interpretación, potencial y déficits del registro fósil, que en la descripción del mismo. Igualmente, la fundación de la revista Paleobiology en 1975 materializó "la rebelión autoconsciente contra la paleontología tradicional” (Fastovski, 2009, p. 243).

En el marco de esos movimientos sociales, la denominada "segunda ola del feminismo" ejerció una considerable influencia en los círculos académicos universitarios. Se abrieron amplios debates sobre las causas de la subordinación femenina y su relación con el patriarcado y el capitalismo, y sobre la identificación de sesgos androcéntricos en la práctica profesional, investigación e interpretación científica como temas fundamentales (Gamble, 2004; Henry, 2012). Desde el feminismo se vertieron críticas sobre todas las ciencias, en particular sobre las ciencias humanas y sociales, por entender que, al estudiar el ser humano, eran más susceptibles de presentar este tipo de sesgos. El rechazo a la arqueología tradicional, por ejemplo, caracterizada hasta entonces por un marcado sesgo androcéntrico, etnocéntrico, nacionalista, racista y clasista (Wylie, 1997), favoreció la incorporación de perspectivas de género en las décadas siguientes (Conkey \& Spector, 1984), lo que supuso, no sin grandes reticencias e intensos debates, una auténtica revolución a nivel teórico y práctico en la disciplina (Preucel \& Hodder, 1996).

La paleontología nunca se encontró bajo un foco semejante. Las particulares características de su objeto de estudio y la objetividad inherente a su condición de ciencia natural parecían aislarla de las influencias de su entorno social. Sin embargo, el análisis crítico de la teoría y la práctica en cualquier disciplina ha demostrado que los sesgos que caracterizan la sociedad patriarcal han tenido una influencia capital en el desarrollo de todas las ciencias (Harding, 1986; Crasnow et al., 2018). La paleontología no es una excepción. Como cualquier otra ciencia, es producto y reflejo de la sociedad en la que se desarrolla, por lo que sus ideas han ido cambiando a medida que el contexto social también lo hacía (Fastovsky \& Weishampel, 2009). Los intereses y corrientes sociales, culturales, políticas, religiosas, etc. de cada momento la han influido, directa o indirectamente, a todos los niveles, desde la teoría a su quehacer cotidiano (Fastovsky, 2009), sobre todo por medio del denominado "sesgo implícito", es decir, los valores, prejuicios y estereotipos que inconscientemente influyen en las personas y en sus actividades (Stigall, 2017).

Toda actividad humana está orientada por valores, representaciones subjetivas de la realidad (Bate, 1998), aunque mientras que unos la representan otros la distorsionan o silencian aspectos de la misma (Harding, 1986). La influencia social determina qué datos y hechos se tienen en cuenta y cuáles no, al igual que su descripción cambia según la sociedad y el observador. La defensa a ultranza de la objetividad, por tanto, obviando que las personas son subjetivas en esencia, es "un vano intento por ocultar los juicios de valor o los objetivos práctico-políticos, éticos o religiosos que se encuentran, ineludiblemente, detrás, y que incluso podrían responder a oscuros intereses individuales o de grupos sociales cuyos fines son públicamente indefendibles" (Bate, 1998, p. 3031). Como la discriminación y subordinación de la mitad de la población a causa de su sexo. 
Desde el feminismo se ha analizado la realidad para detectar los sesgos androcéntricos y las diversas estrategias en que se basan con el fin de rebatirlos, corregirlos o desmantelarlos (Gómez, 2006), al mismo tiempo que señala la discriminación de la mujer a nivel histórico, laboral, etc. Si el feminismo es "una reflexión y distintas prácticas que resultan de dicha reflexión" (Cruz Berrocal, 2009, p. 25), su importancia en las ciencias radica, precisamente, en su capacidad para reflexionar, analizar y cuestionarlo todo con y desde otra mirada, ajena a los estereotipos sexistas tradicionales.

En este artículo se describe la manera en que los sesgos asociados a la ideología patriarcal se han manifestado en la paleontología. Se incide en la interacción bidireccional que se ha producido entre la paleontología y la sociedad, cuyos efectos han sido poco estudiados (Fastovsky, 2009). El análisis crítico lleva implícito una reflexión sobre la influencia de los valores personales y contextuales, así como sobre la necesidad de incorporar la perspectiva de género durante el proceso de investigación y transmisión del conocimiento paleontológico, con el objetivo de hacer una ciencia inclusiva y libre de prejuicios.

\section{UNA MIRADA FEMINISTA Y DE GÉNERO EN LA INVESTIGACIÓN EN PALEONTOLOGÍA}

La incidencia del feminismo en las diferentes ciencias ha sido desigual. Se observa en el grado de aceptación de sus postulados; al comparar cómo unas u otras han respondido ante sus reivindicaciones; en la resistencia al cambio, o en los momentos en los que este se ha producido.

En la paleontología, su influencia en un primer momento se centró, sobre todo, en destacar, visibilizar y poner en valor la aportación de las paleontólogas a la historia de la disciplina (Aldrich, 1982; Torrens, 1995; Emling, 2009), así como en cuestionar el papel dado tradicionalmente a la mujer en la evolución y desarrollo de la humanidad (Slocum, 1975; Tanner \& Zihlman, 1976; Zihlman, 1978; Hager, 1997b; Martínez Pulido, 2012).

El ámbito de las críticas se ha extendido hacia otros aspectos en los últimos años (Plotnick et al., 2014). Además de insistir en estas cuestiones, se incide cada vez más en analizar la situación de la mujer en la profesión y en su escasa representación dentro de la disciplina; en valorar su contribución y visibilidad en publicaciones y congresos; en el liderazgo de proyectos; en su presencia en órganos directivos académicos y administrativos; en las diferencias con los hombres en las condiciones laborales, salariales, etc., o en los obstáculos a los que se enfrentan en la práctica diaria (Carlson, 2013; Stigall, 2013a, 2013b; Plotnick et al., 2014). Estas críticas, incluso han dado lugar a un proyecto cinematográfico y fotográfico no exento de ironía, The Bearded Lady Project: Challenging the Face of Science (http://thebeardedladyproject.com/), cuyo objetivo es destacar el trabajo de las paleontólogas y poner de manifiesto los desafíos y dificultades a los que se enfrentan a diario durante su vida profesional por el solo hecho de ser mujeres.

La evolución de la paleontología en estas cuestiones es innegable y positiva, como se observa en que algunas de las sociedades paleontológicas más importantes del mundo (Society of Vertebrate Paleontology, European Association of Vertebrate Palaeontologists, The Palaeontological Association, etc.) hayan realizado encuestas, talleres y reuniones en sus congresos anuales para debatir y concienciar sobre estos temas, aunque sigue habiendo déficits por corregir. La presencia principal de las paleontólogas como autoras en publicaciones, en la dirección de proyectos o en cargos ejecutivos continúa muy por debajo de su capacidad y número, permaneciendo relegadas en niveles de colaboración y no de liderazgo y responsabilidad (Stigall, 2013a), siendo notable que aún no se haya producido un cambio significativo o un reemplazo ni siquiera equitativo (Plotnick et al., 2014).

Las críticas, por tanto, han sido principalmente de carácter diagnóstico y reprobatorio, señalando más la forma en la que se materializa la desigualdad que el sustrato en el que se reproduce. Mientras que en otras disciplinas se ha intentado converger hacia un análisis integrado que combine las críticas de equidad con las críticas de contenidos (Wylie, 1997), en la paleontología todavía no se ha realizado una propuesta semejante que equilibre ambos aspectos, ni se ha incidido lo suficiente en analizar las causas de la presencia de los sesgos androcéntricos y en la manera en que se han manifestado y difundido o en hacer una relectura de los trabajos anteriores.

\subsection{Los sesgos androcéntricos en la interpretación paleontológica}

Los sesgos asociados con la ideología patriarcal pueden manifestarse de forma soterrada e inconsciente a lo largo de todo el proceso de investigación, sea en la selección y en cómo se abordan determinados temas; en la metodología utilizada; en el lenguaje, conceptos e imágenes usados para describir, interpretar y difundir los hallazgos paleontológicos, y sobre todo en la divulgación de este conocimiento. El uso de determinadas inferencias, por ejemplo, podría reproducir estereotipos de género o llevar a interpretaciones sesgadas sin ser conscientes de ello, especialmente en relación a la adscripción sexual de ciertos comportamientos o rasgos morfológicos y funcionales en animales extintos.

Tradicionalmente se ha asumido que rasgos y comportamientos pudieron haber sido similares a los de 
ciertos animales actuales y que podrían, por tanto, inferirse a partir de lo conocido (Molnar, 1977; Boucot, 1990). Estas interpretaciones suelen derivar de hipótesis planteadas desde el estudio del registro fósil y la biología comparada, sea por homología o analogía (Padian \& Horner, 2011; Horner, 2012). La paleontología es sumamente cauta al hacer tales inferencias, por lo que suelen estar ampliamente sustentadas, del mismo modo que extrema el cuidado en el lenguaje que utiliza, que remite a que las conclusiones nunca son definitivas y están siempre abiertas a nuevos datos. La cautela está justificada. Ya Darwin (1859, p. 279) señaló en su día "la extrema imperfección del registro geológico", a menudo incompleto e incapaz de mostrar íntegramente el desarrollo evolutivo de todas las especies, algunas de las cuales seguramente no quedaron fosilizadas y su existencia se desconoce. Asimismo, la información también podría estar incompleta por motivos ajenos al propio registro, sea por la elección de las zonas de muestreo, los recursos y medios disponibles, etc. E incluso, a veces lo que parece evidente puede no serlo. El ejemplo del caparazón de las tortugas es ilustrativo. $\mathrm{Su}$ origen, formación y función se ha debatido durante décadas (Gilbert et al., 2001; Lyson et al., 2013; Schoch \& Sues, 2015; Lyson et al., 2016). La función actual y más evidente es la protección frente a sus depredadores. $\mathrm{Su}$ función en el pasado pudo haber sido la misma, aunque los últimos hallazgos señalan que posiblemente el desarrollo de un caparazón no tuvo una funcionalidad original de protección del animal, sino que le ayudaría a excavar con mayor eficiencia, al mismo tiempo que facilitaría una mejor adaptación al medio acuático, decisiva para su supervivencia (Lyson et al., 2016).

\subsection{Los sesgos androcéntricos y la interpretación de los dinosaurios}

Un ejemplo de comportamiento inferido es del Pachycephalosaurus, cuyo cráneo presenta un considerable engrosamiento del hueso de la bóveda craneal, cuya explicación ha sido ampliamente debatida (Maryanska et al., 2004). El comportamiento de los bóvidos y otros artiodáctilos y la anatomía comparada sirvieron para interpretar este engrosamiento (Snively \& Theodor, 2011). Se entendió como una respuesta ante las embestidas frontales que los machos mantenían con otros machos de su misma especie en luchas por rango, territorio o apareamiento con las hembras (Colbert, 1955; Galton, 1971; Sues, 1978). También se ha propuesto que las embestidas podrían haber sido en los flancos (Sues, 1978; Carpenter, 1997) y otras posibles funciones, como la termorregulación (Rigby et al., 1987) o la exhibición (Knell \& Sampson, 2011), que actuaría al mismo tiempo de identificación sexual y reconocimiento de la especie (Goodwin \& Horner, 2004).
En algunas bóvedas de pachycephalosauridos se han encontrado patologías de impacto que, sin descartar otras posibilidades, son difíciles de explicar en contextos que no sean combates frontales, probablemente intraespecíficos, aunque no necesariamente debieron de darse entre machos (Peterson et al., 2013). Por otro lado, que la ausencia de este tipo de lesiones en ejemplares sin estas bóvedas craneales se haya interpretado porque "presumiblemente" son juveniles o hembras, se debe tan solo a que es congruente con la inferencia de partida, es decir, que en los bóvidos actuales el combate intraespecífico ocurre con mayor frecuencia entre los machos adultos (Peterson et al., 2013). Por tanto, aparte de la inferencia, ¿qué sustenta asociar las bóvedas gruesas con los machos?

En principio, no parece haber suficientes argumentos que apoyen esta afirmación (Padian \& Horner, 2011). Este tipo de estructuras, aunque similares en muchos aspectos a otras en animales actuales, no por ello son análogas (Padian \& Horner, 2011). En realidad, en este caso "ningún animal existente presenta una morfología similar" (Peterson et al., 2013, p. 1). Asimismo, la mayoría de los ejemplares están incompletos, lo que complica las interpretaciones de tipo ontogénico o sexual (Sullivan, 2006), y los restos con diferentes engrosamientos, atribuidos a especies distintas o a sexos diferentes, podrían referirse a la misma especie en diferentes etapas de crecimiento (Horner \& Goodwin, 2009; Goodwin \& Evans, 2016).

Por otro lado, es relativamente frecuente intentar precisar el sexo en los dinosaurios a partir del dimorfismo sexual, es decir, de diferencias morfológicas, fisiológicas y/o de comportamiento entre machos y hembras de una misma especie, sobre todo en época adulta (Mallon, 2017). Su identificación sería clave para esclarecer las clasificaciones, precisar la función de ciertas partes anatómicas, comprender posibles organizaciones sociales, demográficas y dinámicas poblacionales, o el papel de la selección sexual en la evolución (Larson, 1994; Isles, 2009; Mallon, 2017).

El dimorfismo sexual está bien documentado en animales actuales (Fairbairn et al., 2007), mientras que en los dinosaurios no se ha podido establecer de forma concluyente (Padian \& Horner, 2011). Diferenciar por sexo es una cuestión compleja, por lo incompleto del registro, la escasez de ejemplares, las limitaciones metodológicas o porque buena parte de los rasgos para precisarlo se pierden en el proceso de fosilización (Chapman et al., 1997; Larson, 2008; Schweitzer et al., 2008; Isles, 2009; Brusatte, 2012; Mallon, 2017). En la actualidad se acude a evidencias como la presencia de huevos y embriones o del hueso medular (Schweitzer et al., 2005, 2016). Se supone que con una muestra lo suficientemente grande, estos datos y las morfologías asociadas con la gestación permitirían tener una "imagen de búsqueda" que definiera los sexos (Mallon, 2017). 
Un ejemplo clásico de posible dimorfismo sexual en dinosaurios es un estudio de 24 cráneos de Protoceratops andrewsi (Dodson, 1976). A partir del análisis de las medidas de varios rasgos (ancho y alto de la gola transcraneal, ancho postorbital del cráneo y altura del cuerno nasal) se determinó que las formas más anchas, altas y prominentes eran indicativas de los machos, mientras que las hembras tenían una gola más estrecha y baja, un menor ancho postorbital y un cuerno menos abultado. Se entendía que estos rasgos sirvieron de reconocimiento visual para la atracción de las hembras y la repulsión de otros machos o depredadores rivales. Dodson (1976) cita referencias previas sobre el dimorfismo sexual en Protoceratops y la atribución de ciertos rasgos a un sexo u otro, pero al establecerlo en su estudio no especifica cuáles son sus propios criterios, salvo que atribuye los rasgos mayores (más alto, más ancho) a los machos.

Por el contrario, otro estudio de 29 cráneos de Protoceratops andrewsi no encontró diferencias estadísticamente significativas que indicaran dimorfismo sexual, concluyendo que las diferencias se explicaban por cambios debidos al crecimiento, variaciones en la etapa adulta o por la propia evolución más que por el sexo del animal (Maiorino et al., 2015). En este tipo de estudios suele confundirse la variación individual con dimorfismo sexual (Mallon, 2017), e incluso en los casos posibles, lo limitado del tamaño de la muestra impide en la práctica una rigurosa comprobación de la hipótesis (Maiorino et al., 2015).

Otro ejemplo de posible dimorfismo sexual es un estudio sobre las diferencias morfológicas de las placas óseas que Stegosaurus mjosi presenta desde el cuello hasta la cola (Saitta, 2015). Se tomó como referencia a los bóvidos actuales, al entender que la ornamentación involucrada en la selección sexual de especies existentes puede utilizarse para definir la función de algunas ornamentaciones de dinosaurios. De este modo, se atribuyeron al macho las placas más grandes, anchas y redondeadas, destinadas más a crear una amplia superficie de exhibición que para ser utilizadas en competencias con otros machos, por lo que sobre todo servirían para ser vistas y atraer a las hembras. Por el contrario, las placas más pequeñas, estrechas y altas corresponderían a las hembras y tendrían funciones defensivas (Saitta, 2015) (Fig. 1).

El propio Saitta (2015) reconoce que por las particulares características del animal ninguna inferencia desde una especie existente permite una analogía perfecta. Su uso, además, genera a menudo interpretaciones que van más allá de lo que podría concluirse a partir de los datos (Isles, 2009). En este caso, la asignación del sexo, una vez más, deriva sobre todo de la propia inferencia. Centrarse en ella, por lógica o evidente que parezca, excluye otras opciones y limita la interpretación a una sola línea explicativa. Por ejemplo, afirmar que "se espera que los machos inviertan más energía [que las hembras] en crecer y mantener su
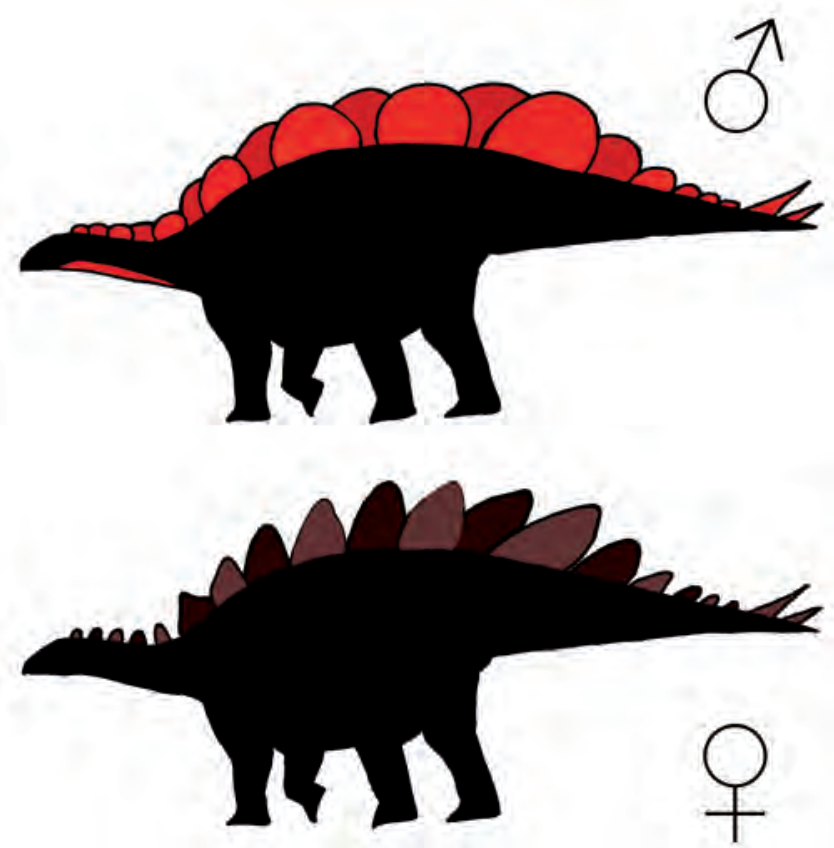

Figura 1. Adscripción sexual de las diferencias morfológicas en las placas óseas de Stegosaurus mjosi. Siluetas hipotéticas asociadas a macho y hembra (Saitta, 2015).

ornamentación" (Saitta, 2015, p. 5), se explica por la hipótesis planteada, a pesar de existir en la naturaleza otras posibilidades, incluso más afines desde un punto de vista filogenético. En aves poliándricas y otras especies de aves, pero también en peces como el pez pipa e incluso en mamíferos como las hienas, las hembras invierten mayor energía que los machos en desarrollar comportamientos y caracteres sexuales secundarios para la selección sexual (Amundsen, 2000; Clutton-Brock, 2007, 2009; Flanagan et al., 2014; Murray et al., 2018), incluso en competencia con otras hembras (Rosvall, 2011). Este comportamiento, denominado "inversión de roles sexuales" (Ah-King \& Ahnesjö, 2013), ha recibido escasa atención (Amundsen, 2000; Clutton-Brock, 2007), quizás porque cambia los roles tradicionales asociados con las estrategias sexuales estereotipadas de hombres y mujeres (Ah-King \& Ahnesjö, 2013). Por ello, Darwin (1871, p. 397) los consideraba "casos anómalos", porque las hembras asumían caracteres (y actitudes) que entendía eran propias de los machos.

Tyrannosaurus rex, por su parte, es quizás el dinosaurio más conocido por el gran público y de los más estudiados por su relativa abundancia en el registro fósil y la excelente conservación de algunos ejemplares. Se ha intentado identificar el sexo a partir de la ornamentación craneal, construcción pélvica, morfología esquelética, presencia de huevos en los arcos pélvicos, erosión del fémur tras liberar el calcio para los huevos, etc. (Molnar, 2005; Larson, 2008). La mayoría de los estudios consideran que las hembras probablemente tenían mayor talla que los 
machos (Carpenter, 1990; Larson \& Frey, 1992; Larson, 1994, 2008; Molnar, 2005). Otra posibilidad es que ambos sexos tuvieran un tamaño similar y que las diferencias se deban, sobre todo, a variaciones entre ejemplares de distintas edades u orígenes geográficos diferentes (Brochu \& Ketcham, 2003).

A pesar que posiblemente las hembras fueran más grandes y robustas que los machos, ¿por qué persiste en el imaginario popular la figura de un enorme macho agresivo, poderoso y carnívoro? (Noble, 2016). Es posible que la proyección de una visión antropocéntrica en la biología induzca a asociar de forma inconsciente aspectos del comportamiento o características físicas de animales extintos con aquello que nos es más afín y conocido, como son los mamíferos, de modo que los ejemplares más grandes y robustos son considerados machos porque es lo más habitual en nuestro propio linaje (vertebradosmamíferos-primates) (Raath, 1990). No resulta extraño, por tanto, que las grandes dimensiones y enormes cráneos y dientes de Tyrannosaurus rex, que de inmediato lo asociaron con un gran depredador carnívoro, "el más grande que haya habitado la tierra" (Anónimo, 1910), indujeran a pensar en este animal como un gran macho, de igual modo que otro gran depredador carnívoro, Allosaurus, es conocido popularmente como "el león del Jurásico". Los estudios que afirmaban el mayor tamaño de las hembras de Tyrannosaurus rex rompieron esta asociación tradicional y desafiaron "el punto de vista chovinista del macho-mamífero" (Larson, 1994, p. 144).

Es de destacar el rigor científico con el que han sido descritos los fósiles de Tyrannosaurus rex desde los primeros estudios (Osborn, 1905, 1906), así como la ausencia de valoraciones especulativas con respecto al sexo de los hallazgos, tanto como el hecho que se nombrara rex y no regina. El motivo, de ahí su nombre, posiblemente se halla en la imagen de poder que transmitía, en sintonía con el contexto imperialista y colonialista en el que se enmarcan los descubrimientos hasta mediados del siglo XX, del mismo modo que el uso inconsciente de pronombres masculinos en algunas descripciones enlazaba con un clima social propicio a asociar el poder del animal y el poder masculino (Fastovski, 2009). Estas correspondencias entre presente y pasado, sociedad y paleontología, e incluso entre ficción y ciencia, demuestran hasta qué punto entre todas han forjado la "naturaleza" de los dinosaurios, creando por ejemplo las connotaciones de masculinidad, agresividad, supremacía y dominación con las que se ha caracterizado a este dinosaurio en concreto y que, en gran medida, continúan presentes (Noble, 2016).

En la entrada principal del Manchester Museum se expone una réplica de Tyrannosaurus rex denominada Stan (por su descubridor Stan Sacrison), que sustituyó a un Tenontosaurus tilletti, un dinosaurio de menor tamaño y herbívoro. Al margen de su sexo real, Stan proyecta una identidad masculina relacionada con el poder y la asociación entre el consumo de carne y la masculinidad (Machin, 2008). Este es un tema ampliamente discutido por el feminismo al contribuir a la estructuración de los roles de género (Adams, 1990; Birke, 1994). Dado que socialmente se relaciona lo herbívoro con el vegetarianismo y el veganismo, opciones alimentarias identificadas como mayoritariamente femeninas (Love \& Sulikowski, 2018), sustituir un herbívoro por un carnívoro significaba cambiar de modelo ante el público (Machin, 2008).

En todos estos casos se observa la importancia de incorporar una mirada de género que abra el campo de las hipótesis, dado que parece existir una tendencia a considerar a priori como macho a cualquier espécimen hasta que las pruebas indiquen lo contrario (Fastovsky, 2009). Esto es más evidente en los ejemplares de mayor tamaño y peso, con ornamentaciones más llamativas, los cuernos más grandes y largos, las mayores placas, garras, dientes, etc. (Larson, 1994), es decir, aquellos que presentan características de fuerza y poder o asociadas con la iniciativa en la selección sexual que se atribuyen tradicionalmente al sexo masculino. Sin embargo, "si la variación morfológica es sexual, ¿qué forma representa a qué sexo?" (Raath, 1990, p. 102). Esta es una pregunta clave, porque es "tentador", como ya se ha apuntado, considerar como machos las formas más grandes, robustas y activas, por la tendencia a pensar que es lo "normal", por lo que afirmar que son machos, a pesar de las excepciones, es lo fácil (Raath, 1990).

Resulta pertinente destacar que, como concepto contrapuesto al dimorfismo sexual, se contempla el dimorfismo sexual invertido o inverso, que señala una situación en la que son las hembras las que tienen mayor tamaño que los machos de su misma especie (Ralls, 1976). Al igual que la "inversión de roles sexuales" (Ah-King \& Ahnesjö, 2013), el término "inverso" podría reflejar un sesgo androcéntrico, especialmente en primatología, donde su uso se explica porque responde a una cuestión cuantitativa que expresa una realidad diferente a la que es estadísticamente mayoritaria en nuestra especie (Plavcan, 2001). Pero esto no explica por qué se utiliza de forma general.

Si bien el dimorfismo sexual en tamaño es porcentualmente mayor en favor de los machos en la mayoría de los vertebrados, sobre todo en mamíferos y, particularmente, en primates (Plavcan, 2001; Fairbairn et al., 2007), no lo es tanto en las otras clases. Tampoco si se cambia la escala de observación a grupos más reducidos dentro de cada una de ellas, en donde los casos son variados. Existe dimorfismo sexual inverso en tamaño, en mayor o menor medida, en todas las clases de vertebrados, como las aves, especialmente en las rapaces (falconiformes y estrigiformes) (Wheeler \& Greenwood, 1983). Incluso entre los mamíferos ocurre con mayor frecuencia de lo que habitualmente se cree (Ralls, 1976). 
Por el contrario, el dimorfismo sexual inverso en tamaño es claramente superior entre los invertebrados (Fairbairn et al., 2007), que multiplican con creces a los vertebrados en números absolutos y de especies, siendo alrededor del 95\% del total de los animales actuales (Brusca \& Brusca, 2005). Este predominio en la naturaleza pone en duda que el concepto se deba solo a una cuestión cuantitativa, como justificaba Plavcan (2001), sino que se trata de un sesgo subyacente en el pensamiento científico. El término inverso describe una realidad que, aunque mayoritaria en la naturaleza, es el reverso de lo que la comunidad científica considera "normal" (Jehl \& Murray, 1986). De este modo, la realidad se tergiversa y se demuestra, una vez más, que la terminología es reflejo de la ideología.

La Real Academia Española define lo inverso como lo alterado, lo trastornado. E invertir se entiende como un cambio de posición, orden o sentido de las cosas, sustituyéndolas por un contrario. No es casual ni inocente que se utilice estos términos en un determinado orden jerárquico. Se pretende con ello situar lo femenino como contraposición y en situación subordinada, para no reflejar una realidad en donde aventaja a lo masculino en algún aspecto. Se trata, en definitiva, de no subvertir un orden establecido que focaliza la atención en lo masculino, invisibiliza lo femenino y establece unos marcos de comportamiento para cada sexo que pueden convertirse en estereotipos de género y acabar siendo utilizados en el momento de realizar ciertas inferencias.

Las interpretaciones sobre los cuidados parentales son un ámbito propicio para ello. En 1978 se encontró en Montana (Estados Unidos) una posible colonia con cáscaras de huevos y restos juveniles de hadrosaurios, aparentemente de la misma especie y tamaño, y con cráneos semejantes a un cráneo de hadrosaurio adulto hallado en las cercanías (Horner \& Makela, 1979; Horner, 1982). Al interpretarse que podía estar cuidando de la colonia, aun sin conocer su sexo se asumió que debía tener un nombre en clave femenina: el ejemplar se denominó Maiasaura peeblesorum, "reptil buena madre" en griego (Horner \& Makela, 1979) (Fig. 2). La anidación se comparó con la que practican cocodrilos y aves, pero no se acudió a estas en cuanto a los cuidados, a pesar que la estrecha relación filogenética de las aves con los dinosaurios podría incluir rasgos de comportamiento con respecto a los cuidados parentales (Varricchio et al., 2008). En tal caso, la atención pre y postnatal pudo haber sido biparental, mayoritaria entre las aves, o no ser exclusiva de las hembras, que aunque en menor porcentaje tampoco es extraña (Clutton-Brock, 1991; Cockburn, 2006). En definitiva, se nombró el hallazgo a partir de un estereotipo.

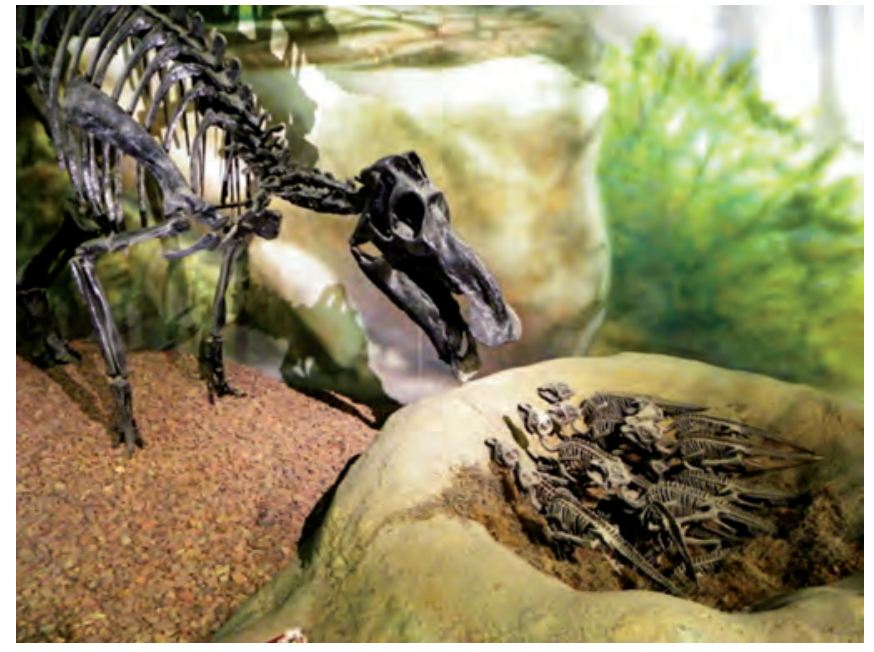

Figura 2. Reconstrucción de Maiasaura peeblesorum cuidando de sus crías. Wyoming Dinosaur Center, Thermopolis, Wyoming.

\subsection{Los sesgos androcéntricos y el proceso de hominización}

Aunque los comportamientos y rasgos de los animales extintos debieron de ser tan complejos y variados como lo son en la actualidad, la influencia del dogma androcéntrico limita las opciones, restringe la visión del pasado y condiciona las interpretaciones. Un ejemplo de estas limitaciones se encuentra en la lectura de la evolución humana, el llamado proceso de hominización, que ya de por sí es toda una declaración de intenciones.

La paleoantropología designa con la categoría taxonómica del género Homo a todas las especies humanas, lo que incluye, evidentemente, a los dos sexos de cada una de ellas. Igualmente sucede con el término "hombre" al ser un masculino genérico, aunque su uso es tan conscientemente difuso que a menudo es difícil distinguir si se refiere solo a los varones o a toda la especie (Slocum, 1975; Argelés et al., 1991). Por ejemplo, de entre las 100 primeras imágenes que resultan al buscar la palabra "hombre" en internet, 98 son masculinas y 2 son femeninas, los mismos números que para "Hombre de Neanderthal", mientras que son 96 y 4, respectivamente, para Homo sapiens $(15 / 09 / 2019)$. No es, por tanto, la imagen de la mujer la que se visualiza al usar estos términos, porque hombre significa realmente varón (es decir, macho de la especie humana). Cuando Childe (1936), en Los orígenes de la civilización, mencionaba 52 veces la palabra "hombre" y ninguna la palabra "mujer", manifestaba una interpretación del pasado determinada por la ideología patriarcal, una de cuyas premisas es generalizar lo masculino como medio para ocultar lo femenino. 
Si la creación bíblica de la humanidad mostraba a un Dios formando al hombre a su imagen y semejanza, la interpretación tradicional de la evolución humana se ha centrado también en su figura, en la creencia en una supuesta superioridad del macho/hombre sobre la hembra/ mujer, lo que le haría ser más apto para las tareas complejas, como la caza o la fabricación de herramientas. Darwin (1871, p. 316) sostenía que "el hombre es más valiente, agresivo y enérgico que la mujer, y tiene mayor inventiva", consiguiendo "mayor excelencia que la mujer en cualquier cosa que emprenda, tanto si se requiere pensamiento profundo, raciocinio o imaginación, o simplemente el empleo de los sentidos o las manos" (Darwin, 1871, p. 327). Es evidente que Charles Darwin vivió y escribió en una época en donde afirmaciones semejantes eran comunes y la superioridad masculina se consideraba un hecho incuestionable. La trascendencia de sus comentarios reside en la gran influencia que su obra ha tenido en autores posteriores, que incluso ya entrado el siglo XXI siguen mostrando sesgos androcéntricos similares. Este tipo de afirmaciones legitimaban la discriminación y han servido para establecer un "techo de cristal paleolítico" sobre la mujer (Zihlman, 1997), que ha ignorado su aportación a la subsistencia y su rol en la evolución humana (Hager, 1997a). Igualmente, reafirmaban la llamada "división sexual del trabajo", ampliamente criticada (Liebowitz, 1986; Argelés et al., 1991; Kuhn \& Stiner, 2006), que definía al hombre como agente activo del cambio (Hager, 1997a), sobre todo en su faceta de proveedor de alimentos, es decir, como cazador (Lee \& Devore, 1968).

Cuál fue la principal fuente de sustento de los primeros homíninos y sus consecuencias ha generado intensos debates durante décadas (Washburn \& Devore, 1961; Lee \& Devore, 1968; Binford, 1981; Lovejoy, 1981; Shipman, 1986; Blumenschine \& Cavallo, 1992; etc.). Inicialmente prevaleció la hipótesis que la ingesta de carne fue el elemento decisivo que favoreció el desarrollo físico, cognitivo y social de la especie, el bipedismo y el lenguaje, la conducta humana y el gregarismo (Dart, 1953; Krantz, 1968; Lee \& Devore, 1968; Ardrey, 1976; Stanford, 1999). Esta relación causa-efecto exaltaba el modelo tradicional del hombre cazador defendido en Man the Hunter (Lee \& Devore, 1968), y omitía o desdeñaba "el papel de las mujeres como proveedoras y su contribución al éxito del Homo sapiens" (Zihlman, 2012, p. 275). Este modelo/mito se consideraba tan incuestionable por motivos ideológicos que impedía avanzar hacia lecturas más inclusivas o simplemente diferentes. Woman the Gatherer (Slocum, 1975; Tanner \& Zihlman, 1976) no solo se planteó como una hipótesis científica sino como una alternativa igualmente válida que permitía elaborar una narrativa distinta. En esta "otra" historia, la mujer se situaba en el centro de la evolución y adquiría el protagonismo anteriormente negado (Fig. 3). Las características humanas pudieron surgir, de este modo, de forma diferente a la explicación tradicional, esta vez en torno a aspectos estrictamente femeninos, como el vínculo entre hembras y crías, el parto asistido entre hembras o la lactancia colectiva, dado que el éxito evolutivo requería del éxito reproductor, es decir, de la implicación de las hembras en la reproducción y supervivencia de su progenie (Martínez Pulido, 2003, 2006, 2012; Barros del Río et al., 2015). Sin esta participación, es posible que la especie no hubiera sobrevivido ni desarrollado las relaciones sociales tal y como las conocemos.

A pesar de la controversia, la herencia del paradigma del hombre cazador sigue presente en la percepción de las sociedades prehistóricas a nivel popular, porque es la que se ha difundido en los museos, exposiciones, libros de texto y de divulgación, comics y películas. Esta caza se ha presentado como un acto alejado de lo instintivo y, por supuesto, del carroñeo, considerado propio de los animales. Presentar a los homíninos como grandes cazadores significa elevar su condición de animal a humana y reafirmar el éxito evolutivo del ser humano, aunque la teoría del hombre cazador "se basa más en prejuicios sexuales y de otro tipo que en el registro fósil y en la ecología de la búsqueda de alimentos" (Blumenschine \& Cavallo, 1992, p. 90), al ser una mera proyección de modos de vida y sesgos actuales que crean asociaciones del tipo hombre/caza y mujer/recolección.

Este reparto de roles no necesariamente tuvo que darse de este modo (Adovasio et al., 2007). Existen ejemplos etnográficos que muestran modelos alternativos en los que la asignación de actividades se fundamenta más en las aptitudes que en el sexo (Kent, 1998; Weedman, 2010); que la caza, sobre todo menor, fue seguramente compartida (Barros del Río et al., 2015), y en donde "los límites entre los roles económicos son permeables y los individuos pueden pasar de un rol a otro a lo largo de sus vidas" (Kuhn \& Stiner, 2006, p. 954). No usar esos ejemplos como analogías y aceptar solamente el modelo del hombre cazador responde a prejuicios ideológicos y estereotipos, no a datos científicos, lo que convierte el pasado en una construcción cultural (Hager, 1997a; Martínez Pulido, 2006). Incluso cuando se sostiene que las relaciones de parentesco en torno a la mujer/madre pudieron ser clave para la supervivencia (Lovejoy, 1981), se hace sobre una visión tradicional de la familia y una férrea división sexual del trabajo que diluye su importancia, al seguir priorizando el aporte del varón por la caza, mientras que la recolección, asignada a las mujeres, se considera complementaria y residual (Isaac, 1978). Aunque la relevancia de la recolección en los grupos cazadores recolectores ha sido profusamente atestiguada por la etnografía, nunca ha sido reconocida precisamente por entender que fue realizada por mujeres (Berihuete \& Piqué, 2006).

Las diversas reconstrucciones del comportamiento de los primeros homíninos son, quizás, el caso más obvio de androcentrismo en arqueología (y probablemente también 
en paleoantropología), tanto en conceptualización como en el modo de presentación (Conkey \& Spector, 1984, p. 6). Más grave aún ha sido que, al pretender reconstruir el modo de vida de aquellas poblaciones, paleoantropólogos y prehistoriadores han intentado explicar la naturaleza de lo que significa ser un humano moderno, para que al establecer un vínculo entre pasado y presente se comprenda mejor lo que somos. Pero sus consecuencias van más allá de una simple explicación científica, como preguntarse si hombres y mujeres son inherentemente diferentes debido a su particular pasado evolutivo (Hager, 1997a).

La producción del conocimiento científico va más allá del propio conocimiento, siempre es un acto político por las repercusiones que se desprenden (Haraway, 1988). Es probable que la paleontología no haya sido consciente de estas consecuencias. Este tipo de interpretaciones han servido de "paraguas" para justificar y reproducir una ideología que defiende, a partir de esa diferencia, la subordinación, discriminación y opresión de las mujeres como resultado de un proceso biológico (Okruhlik, 1994; Martínez Pulido, 2006). Cualquier intento por cambiar esta situación no solo se consideraba estéril sino incluso contraproducente, pues contradecía una biología que determina el "orden natural", en línea con los sesgos androcéntricos de la obra de Charles Darwin (Okruhlik, 1994).

\section{UNA MIRADA FEMINISTA Y DE GÉNERO EN LA DIFUSIÓN Y DIVULGACIÓN DEL CONOCIMIENTO PALEONTOLÓGICO}

En la concepción lineal del tiempo de la civilización occidental, pasado y futuro se imaginan y recrean a partir del presente, haciendo más rudimentario o tecnológicamente más avanzado el conocimiento actual. Igualmente, hacia un tiempo u otro se proyectan los anhelos, miedos y prejuicios que nos acompañan, por lo que los seres que habitan esos mundos imaginados no dejan de ser, en cierto modo, un reflejo de nosotros mismos. No en vano, desde Platón a Star Trek, son muchos los autores que han situado en esos extremos temporales sus sociedades utópicas, espejos transformados de nuestra realidad.

No es extraño, por tanto, que cuando el pasado remoto es el escenario en la televisión, el cine o la literatura, en revistas de divulgación, comics e incluso en el humor, a menudo estén presentes los mismos sesgos que hallamos en la actualidad. De este modo, son habituales las escenas de agresión, subordinación y humillación hacia la mujer, o el tradicional reparto sexual de roles y estereotipos de género. El varón se muestra activo, cazador y violento,
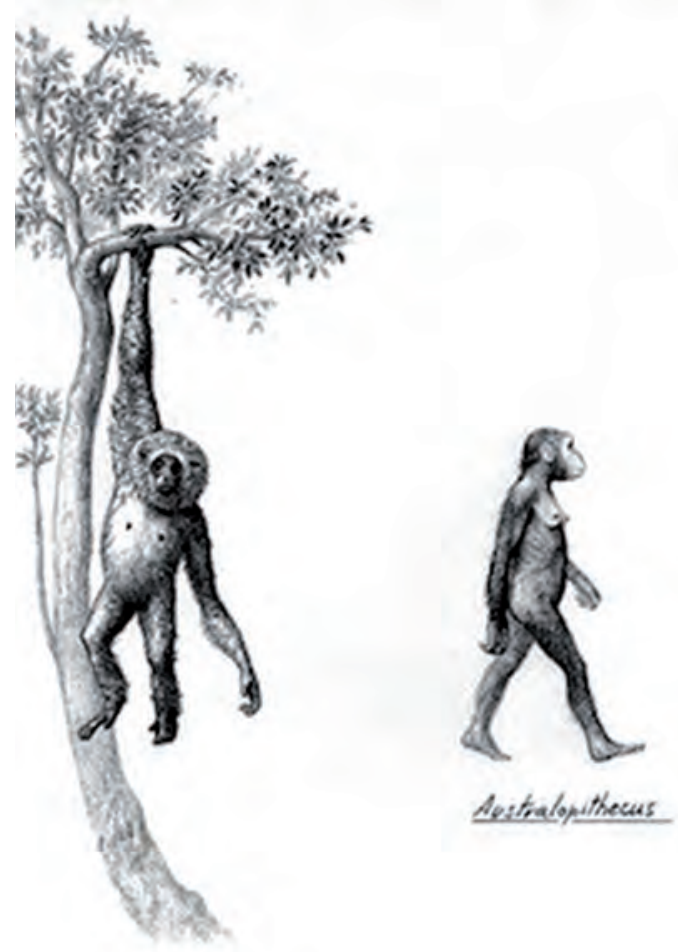

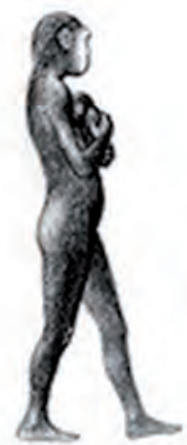

Homno habilis

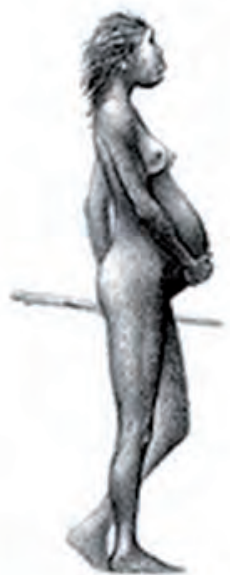

Homs ergastor

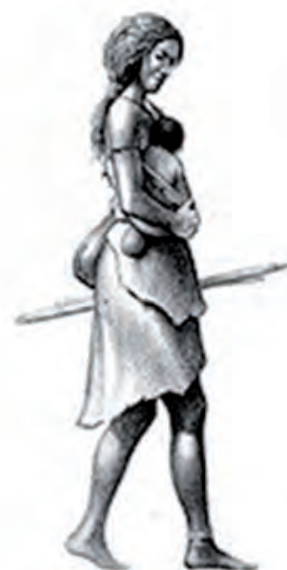

Homo sapiens

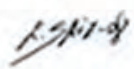

Figura 3. Dibujo que representa la evolución humana utilizando una figura femenina. Ilustración: Eduardo Sainz Alonso (en Barros del Río et al., 2015). 
incluso arrastrando a una mujer del cabello, mientras que esta aparece pasiva, en el entorno doméstico, cuidadora de niños y ancianos, o recogiendo plantas. A través de estos medios de amplia repercusión se introduce un mensaje subliminar que reproduce el modelo patriarcal en el contexto de lo cotidiano. Un mensaje que oculta o caricaturiza la imagen de la mujer en el pasado, minimiza su papel en el desarrollo de las sociedades humanas, y más grave aún, que incluso llega a banalizar la violencia de género.

La responsabilidad de esta situación es compartida, en diverso grado, por quienes generan la información y quienes la reproducen. El conocimiento del pasado se crea a partir de los diferentes medios formativos, formales como la educación, e informales como los medios de comunicación, redes sociales, internet, etc. La mayor parte de la información que se utiliza es proporcionada por la ciencia, por lo que se imparte y divulga como objetiva y cierta. De ahí la importancia que esa información esté libre de prejuicios y sesgos y no contribuya a perpetuar la ideología sexista patriarcal (Argelés et al., 1991).

No obstante, en los textos e imágenes que evocan la vida animal en el pasado remoto, que se refieren al desarrollo de la humanidad o a la vida cotidiana durante la prehistoria, la figura dominante continúa siendo la masculina. Esta interpretación, realizada solamente desde una de las miradas, ha impregnado de tal forma los contenidos que se trasmiten que apenas se es consciente de que se comunica una información sesgada en todos los niveles formativos, pero que es especialmente perniciosa en los textos escolares (Argelés et al., 1991). En la web del Instituto Nacional de Tecnologías Educativas y de Formación del Profesorado del Ministerio de Educación, Cultura y Deporte de España se ofrecen diversos textos elaborados para ayudar al profesorado de Educación Secundaria a preparar sus clases. El primer tema, "Prehistoria e Historia antigua", abre con una página titulada "El gran jefe de los dinosaurios". En los siguientes textos, que abarcan desde el Paleolítico a la España visigoda, las referencias a las mujeres son prácticamente inexistentes. Incorporadas, una vez más, dentro de la categoría hombre, se las invisibiliza.

¿Cómo es posible que en el siglo XXI se repitan las mismas formas de expresión y contenidos que ofrecen una imagen del pasado que parece "fosilizada" desde el siglo XIX? Para Padian (2013), las editoriales son reacias a los cambios, especialmente en cuanto a la evolución humana, porque aparecen constantemente nuevos datos que alteran lo conocido, lo que dificulta la actualización de los redactores y el trabajo de los profesores. Por ello, existe un cierto consenso en presentar los contenidos de manera uniforme, aun siendo conscientes de que puede tratarse de información desfasada, sesgada o incluso incorrecta, pero que acaba siendo reproducida hasta que finalmente es corregida y asumida por todas las editoriales implicadas en la redacción de este tipo de textos.
Por otro lado, igual de importante que el contenido de la información es la forma en la que se divulga. En este sentido, la escasa representación de la mujer en los medios de comunicación cuando tratan temas relacionados con la paleontología es un importante obstáculo de cara a visibilizar socialmente a las mujeres y normalizar su presencia como científicas. Su aparición en documentales, por ejemplo, es casi anecdótica. Walking with Dinosaurs (BBC Worldwide, 1999); Dinosaurs: Giants of Patagonia (Sky High Entertainment, 2007); Dinosaur Revolution (Discovery Channel, 2011); o Bizarre Dinosaurs (National Geographic, 2018), son solo cuatro de los muchos documentales presentados por hombres y en donde los paleontólogos entrevistados son mayoría. Para el público, por tanto, la paleontología es cosa de hombres, lo que hace prioritaria una mayor visibilización que derribe el estereotipo sin tener que recurrir a una barba para cambiar la cara de la ciencia.

La crítica feminista ha señalado situaciones similares de discriminación en todos los medios de comunicación, que sirven de herramienta para la reproducción social de los valores del patriarcado a través de un receptor que es concebido como consumidor pasivo y acrítico (Bernárdez, 2015), por lo que tiende, a su vez, a reproducirlos. La educación con perspectiva de género es fundamental para desactivar este bucle y, en este esfuerzo, los museos tienen la capacidad y la responsabilidad para llevarla a cabo.

Si los sesgos androcéntricos pueden estar presentes en las interpretaciones paleontológicas, es lógico pensar que puedan, igualmente, trasladarse a la difusión de este conocimiento a los museos paleontológicos y de ciencias naturales y de estos al público. Hay que diferenciar, sin embargo, entre la paleontología de animales y plantas y la paleoantropología, pues aunque ninguna está libre de sesgos, es en esta última en donde se presentan de forma más evidente, soterrados en el discurso narrativo y expositivo.

Estos museos despiertan gran interés en los visitantes por la temática atractiva que tratan, la espectacularidad de algunos de los especímenes expuestos $\mathrm{y}$, en los últimos años, por el impacto mediático de ciertas películas. Este es un hecho afortunado que debe aprovecharse, pues "lo que justifica en última instancia la institución de los museos es su compromiso permanente con la educación" (Ballart, 2007, p. 215). Los museos pueden ayudar a entender el lugar que ocupa el ser humano en la naturaleza, el reino animal y la historia de nuestro planeta. Son un medio notable para la concienciación medioambiental, la sensibilización social y la educación científica. Por ello, dado que la educación forma parte de la base que sustenta el pensamiento y los sesgos de todo tipo que perduran en época adulta, incluso en personas formadas, no se concibe que los museos reproduzcan datos erróneos, incompletos o sesgados, que pueden influir decisivamente en la percepción de la realidad y de la sociedad en niñas 
y niños, así como en el mantenimiento de prejuicios e información inexacta en las personas adultas (Spiegel et al., 2012).

En el 2003 se inició en los Estados Unidos el proyecto Explore Evolution, financiado por la National Science Foundation (http://explore-evolution.unl.edu/), que incluía el desarrollo de una galería permanente con siete proyectos de investigación en ciencia evolutiva. El objetivo era aumentar la comprensión pública del concepto de evolución (Spiegel et al., 2012). Se instalaron copias de la exposición en museos del Medio Oeste y Sur de los Estados Unidos, y en uno de ellos se realizó un estudio para examinar si una sola visita contribuía a un cambio conceptual en el razonamiento de los visitantes sobre el tema. Todos aumentaron significativamente el uso de explicaciones basadas en el razonamiento evolutivo, aunque se constató que la influencia de las variables personales, socioculturales y contextuales era tan importante que condicionaba las respuestas, haciendo incluso predecible el razonamiento de las personas encuestadas. Se señaló, asimismo, que en contraste con las más jóvenes, las personas adultas parecían ser más capaces de integrar la información y rechazar las explicaciones intuitivas, que vienen dadas por el contexto personal. $\mathrm{La}$ importancia de este estudio reside en que se concluyó que el cambio conceptual a menudo no se consigue suplantando lo que ya se conoce o las creencias que ya se tienen, sino "afinando" las explicaciones e integrándolas en el proceso de formación del conocimiento (Spiegel et al., 2012). Por tanto, para incrementar la comprensión pública de la parte femenina de la naturaleza y la historia humana, no es tan transcendente hacer exposiciones monográficas sobre estos temas como integrar esta parte, en gran medida ignorada u ocultada, en la creación del conocimiento y en su divulgación.

El trabajo es arduo pues los museos también son hijos de su tiempo. Aunque los museos de paleontología e historia natural, dedicados a comunicar la ciencia, deberían de ser "justos" y "objetivos" en sus exposiciones, presentan sesgos de todo tipo (sexistas, colonialistas, racistas, etc.) en la forma en que representan la naturaleza, a veces de forma inconsciente pero en otras ocasiones de un modo totalmente intencionado (Ashby, 2017).

A modo de ejemplo, en 1947 se produjo el hallazgo del llamado "Hombre de Tepexpan", en México, que levantó gran expectación por su datación (11000-9000 B.P.) y por la aplicación de novedosas técnicas geofísicas (de Terra et al., 1949), así como fuertes críticas por la interesada interpretación política y mediática que se hizo del hallazgo, al difundirse la imagen de un "primer mexicano" muerto heroicamente durante la cacería de un mamut (Lorenzo, 1989). Cuando en 1964 se construyó el Museo Nacional de Antropología de México se reunió esta y otras informaciones en un único diorama. Aunque se conocía que el cráneo de Tepexpan podía haber sido de mujer (Genovés, 1960), esta información se obvió y se presentó la imagen preconcebida con gran éxito de público.

En este tipo de dioramas y en imágenes y representaciones semejantes, a menudo se reflejan visualmente estereotipos de género, roles, valores y actitudes tradicionalmente asociadas con un sexo u otro (Argelés et al., 1991). Hombres/machos aparecen cazando o realizando actividades consideradas propias de su sexo (fabricación de herramientas, ritos religiosos, arte rupestre, etc.), mientras que las mujeres/hembras se representan pasivas, en el hogar, cuidando de sus hijos y recolectando (Gifford-Gonzalez, 1993) (Fig. 4). Es la misma imagen que, como se vio anteriormente, se ha divulgado a nivel popular.

Adovasio et al. (2007) describen el caso del diorama del yacimiento de Laetoli (Tanzania), famoso por el descubrimiento de pisadas de homíninos en 1976. Expuesto en 1993 en el American Museum of Natural History de Nueva York, representaba una pareja de Australopithecus afarensis caminando sobre la ceniza volcánica en un paisaje desolado. Mientras que la hembra miraba atemorizada hacia el lado contrario de un volcán humeante, el macho la rodeaba con su brazo de forma protectora.

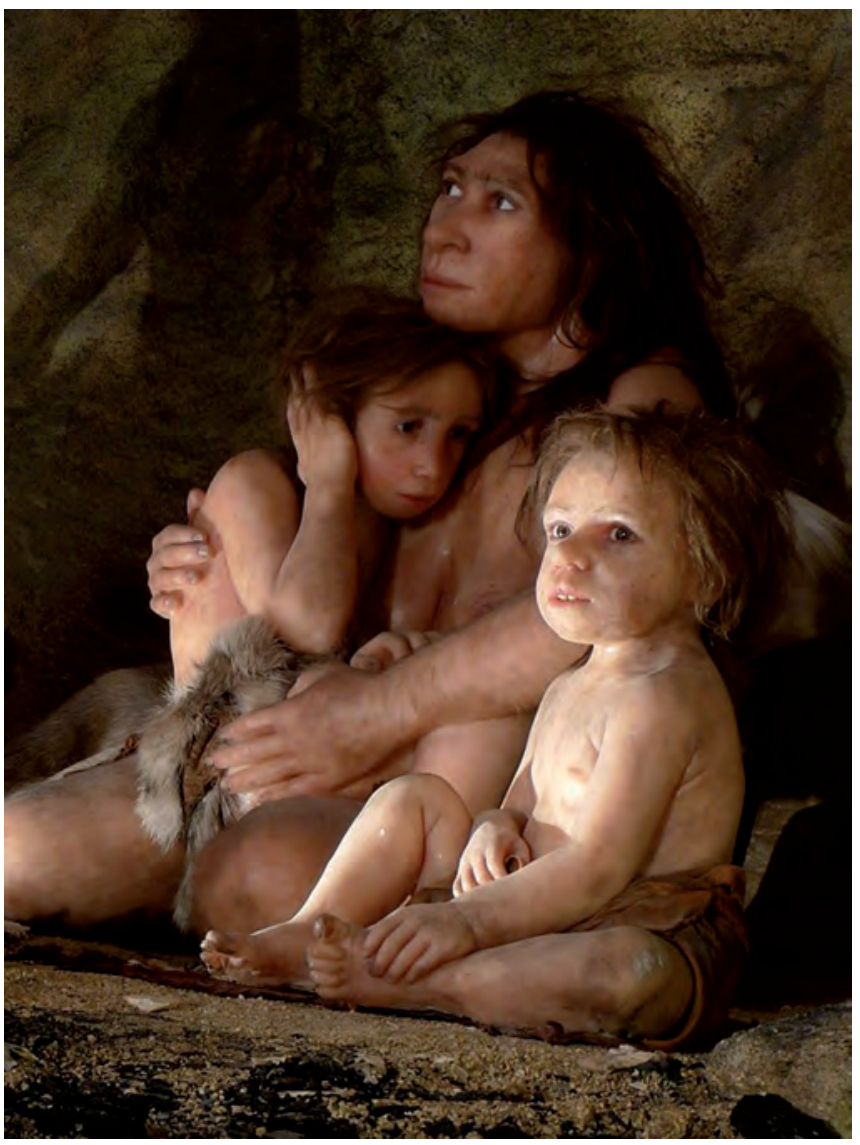

Figura 4. Representación habitual de la figura femenina en la prehistoria. Mujer neandertal cuidando de sus hijos. Museo Neandertal de Krapina, Croacia. 
La estampa levantó las críticas de Zihlman (1997), que la comparó con la escena bíblica de la expulsión de Adán y Eva del Paraíso.

Imágenes parecidas suelen repetirse en este tipo de exposiciones. La ilustración que sirve de fondo a una representación de Homo habilis en el Museo Nacional de Ciencias Naturales de Madrid, en la sala "La evolución humana", muestra un macho caminando delante de una hembra por la sabana africana llevando una especie de lanza de madera. En esta misma sala, todas las figuras son masculinas, salvo el caso excepcional de Lucy, la Australopithecus afarensis descubierta por Donald Johanson en Etiopía en 1974. Muy semejante es la situación en la "Galería de Homínidos" del Museo de la Evolución Humana de Burgos, cuyas reproducciones hiperrealistas son mayoritariamente masculinas.

A nivel general, en los museos paleontológicos y de ciencias naturales, sobre todo en las salas de paleoantropología/prehistoria, se ha mantenido una concepción tradicional que en gran medida ha pasado por alto la presencia de sesgos androcéntricos y situaciones de discriminación. Un estudio realizado en las galerías dedicadas a la historia natural en el Manchester Museum reveló ejemplos de discriminación de género que transmitían una imagen distorsionada del reino animal, apenas perceptible sin un estudio en profundidad (Machin, 2008). Del total de especímenes expuestos en la galería de mamíferos, el $71 \%$ eran machos y solo un $29 \%$ eran hembras. En cuanto a las aves, la relación era de $66 \%$ y $34 \%$ respectivamente. Estos sesgos también se apreciaban en la forma de exponer los ejemplares. Machos y hembras se mostraban juntos solo cuando el tamaño del primero era mayor, pero no cuando sucedía a la inversa. En algunos casos, parecía que las hembras se exponían allí donde ocupasen poco espacio, en vez de donde su función informativa fuera mayor. Además, en las actitudes y posiciones relativas entre ambos sexos, el macho aparecía siempre en posición dominante sobre la hembra, que además ocupaba una posición visualmente inferior. Igualmente, el lenguaje utilizado en los textos interpretativos solía asociar a la hembra con la maternidad y a los machos con la caza, o con un papel más activo que ellas, pero siempre lejos del cuidado parental. Las explicaciones fueron diversas y reflejaban las diferentes opiniones que se tienen sobre cuestiones de género en el ámbito de los museos y, en general, en la sociedad. Finalmente, se realizó una intervención para detectar los sesgos y corregirlos (Machin, 2008).

De igual modo, en la sala dedicada al Cretácico en el Museo Jurásico de Asturias (MUJA) se exponen dos réplicas de Tyrannosaurus rex, macho y hembra, en posición de cópula. La espectacularidad de la escena, de gran impacto visual, difumina el hecho de que es la única posible en la que la hembra, en principio de mayor talla y fuerza, parezca menor que el macho y en posición subordinada. La imagen pasa totalmente inadvertida, soterrada en una escena que refleja un mero acto biológico, cuya espectacularidad nace del lógico interés por atraer visitantes, pero que hace necesario un análisis que vaya más allá de lo evidente para percibirla. Con total seguridad, quienes la diseñaron no contemplaron esta interpretación ni fue esta su intención, como probablemente tampoco la tuvieron los responsables de las situaciones descritas en el Manchester Museum o en los otros museos anteriormente mencionados.

Sin embargo, no es un tema menor. Aunque este tipo de imágenes puedan parecer inocentes, "construyen un paralelismo, una narración visual del pasado humano [o animal] que, debido a su potencia comunicativa, debe tomarse en serio" y deberían de preocupar a los paleontólogos, porque no necesariamente reflejan con fidelidad la información científica que en principio se quería transmitir (Gifford-Gonzalez, 1993, p. 24). Por el contrario, podrían responder a otros intereses, menos científicos, artísticos en el mejor de los casos, pero también ideológicos, hasta el punto de entrar en conflicto con el objetivo general de la divulgación (Gifford-Gonzalez, 1993).

Si uno de los objetivos de los museos es representar con proporcionalidad la realidad de la diversidad animal que ha existido en el planeta o la vida de los primeros humanos, sería lógico suponer que lo expuesto debería aproximarse al $50 \%$ en cuestión de sexo. Sin embargo, no suele suceder. El discurso expositivo continúa centrado en lo masculino, sin que aparentemente el público perciba la inexistencia de lo femenino o de la imagen que se proyecta. Es posible que al querer conectar con el público e incrementar su interés, los museos y los medios de comunicación recurran a discursos e imágenes estereotipadas, que pasan desapercibidas porque son reconocidas y aceptadas por una parte importante de la sociedad. Esta incapacidad para advertir lo invisibilizado o distorsionado nos remite a la interiorización del discurso patriarcal en la sociedad, y hasta qué punto sus valores han condicionado la actividad científica y viceversa, de manera que al reproducirlos se asumen y normalizan. De este modo, la interpretación y reproducción del pasado se convierte en una recreación basada en la constante interacción entre ciencia y sociedad, en la que pasado y presente continuamente se retroalimentan (Fastovsky, 2009; Noble, 2016). Se crea así un bucle de influenciasesgo-influencia que solo puede romperse incorporando la perspectiva de género en la formación de quienes crean y divulgan la información, lo que permitiría evitar, visualizar y corregir los diferentes sesgos.

La crítica feminista ha evidenciado situaciones sesgadas, de subrepresentación u omisión de lo femenino en museos y exposiciones de todo tipo, históricas, antropológicas, arqueológicas, artísticas, etc. Sin embargo, salvo algunas críticas (Gifford-Gonzalez, 1993; Zihlman, 1997; Adovasio et al., 2007), es notable la falta de estudios 
en los museos de paleontología con el detalle del realizado en el Manchester Museum. Este es un déficit que pretende en parte paliar el "Proyecto museológico incluyente con una perspectiva de género para la divulgación significativa de la paleontología y la arqueología", iniciado en 2014 en México por C. Corona (com. pers.). La propuesta incorpora la perspectiva de género al modelo de divulgación significativa del patrimonio centrada en el visitante (Gándara, 2018). Su objetivo es evaluar cómo se divulga la paleontología y la arqueología en los museos de la Ciudad de México y su impacto en los visitantes. Hasta el momento se han recopilado datos del Museo Nacional de Antropología, del Museo de Historia Natural de la Ciudad de México, Museo de las Ciencias de la UNAM (UNIVERSUM) y Museo de Geología de la UNAM. Actualmente el proyecto se encuentra en proceso de análisis y evaluación de los resultados.

El Consejo Internacional de Museos (ICOM) ha reconocido que los objetivos para los museos se encuentran desfasados, asumiendo la labor de realizar una revisión profunda que contemple los retos actuales, entre los que se encuentra la incorporación de la perspectiva de género como uno de los principios de inclusión. Ante la "profunda preocupación por la insuficiente implicación por parte de los museos en materia de género y mujer" (ICOM, 2013, p. 4), en la $28^{\mathrm{a}}$ Asamblea General del ICOM, celebrada en Río de Janeiro en el 2013, se instó a las partes a desarrollar una política de incorporación de la perspectiva de género y garantizar su implementación. Se recomienda (ICOM, 2013, p. 5) que los museos: 1) analicen las narrativas expresadas desde una perspectiva de igualdad de género; 2) trabajen con el público, el personal y los programas desde una perspectiva de igualdad de género $\mathrm{y}$, al mismo tiempo, que las ideas se materialicen con el fin de establecer una política de igualdad de género; 3 ) empleen el análisis interseccional (raza, etnicidad, género, categoría social, religión, orientación sexual, etc.) para hacer viable el concepto de inclusión en los museos.

Debido a la ideología subyacente en los profesionales encargados de la gestión y otros intereses más espurios, ya sean políticos, económicos, ideológicos, etc., los museos se rigen por criterios subjetivos y todos, en mayor o menor medida, presentan sesgos que afectan prácticamente a todos los aspectos del museo y sus exposiciones (Ashby, 2017). La responsabilidad de corregirlos recae en sus profesionales, al ser quienes eligen qué se adquiere, qué se expone y cómo hacerlo. De ahí la importancia de insistir en la formación en perspectiva de género con el fin de que dispongan de las herramientas que permitan filtrar el trabajo museológico y museográfico a través de esta mirada, así como crear discursos expositivos libres de tópicos y estereotipos. Sin una formación inclusiva que contrarreste el discurso androcéntrico dominante, se seguirá reproduciendo un modelo desigual e informaciones inexactas, inapropiadas o, directamente, interesadas.

\section{CONCLUSIONES}

Los diversos ejemplos expuestos a lo largo de este artículo sugieren la presencia velada de sesgos androcéntricos, prejuicios y estereotipos de género en la paleontología. Sucede en la práctica profesional y en el proceso de investigación, en especial en la interpretación $y$, sobre todo, en la divulgación, que es en donde se manifiestan con mayor intensidad.

Aunque se observa que de forma general existe una voluntad explícita por mantener la objetividad científica, también se aprecia que este propósito no evita los efectos de la influencia social, que se transfiere de manera inconsciente por medio del sesgo implícito que describía Stigall (2017), en particular al abordar determinados temas, como la evolución humana. Esta circunstancia puede producir una transferencia de información que, en mayor o menor medida, está sesgada de origen y se traslada como veraz al conjunto de la sociedad a través de los diversos medios formativos y de comunicación, como los museos.

Es de destacar que todavía sean relativamente escasos los estudios críticos sobre este tipo de cuestiones en paleontología y, en concreto, en cómo su información se divulga en los medios, en los ámbitos educativos, libros de texto, museos, exposiciones, etc. Su aparente neutralidad, heredada de la paleontología tradicional, probablemente la ha alejado del necesario proceso de crítica, debate y reflexión. Instalarse, igualmente, en un cierto negacionismo tampoco soluciona la cuestión. Antes al contrario, dificulta estudiar el pasado desde posiciones más inclusivas y abiertas. Una percepción sesgada de la realidad supone un peligro para la propia creación del conocimiento, pues reproduce una ideología que impide la comprensión íntegra y objetiva del pasado. Focalizar la interpretación en una sola dirección empobrece la capacidad de análisis al descartar a priori otras perspectivas igualmente válidas. Es posible ampliar la gama de hipótesis, anteriormente restringidas, $\mathrm{y}$ enriquecer la investigación aceptando alternativas que ya no se centren, exclusivamente, en lo masculino. Aun con un fundamento metodológico impecable, una investigación que no tenga en cuenta estos potenciales condicionantes puede llevar a conclusiones precipitadas, cuando no sesgadas, y a aceptar y difundir finalmente como válidos unos resultados que, estrictamente hablando, se sustentan en una única y particular interpretación.

La perspectiva de género observa el objeto de estudio con una mirada ajena a los estereotipos sexistas. El feminismo propone una reflexión que introduce lo femenino en la ecuación $\mathrm{y}$, al hacerlo, la palabra perspectiva adquiere un significado literal que permite alejarse de las posiciones, actitudes y expresiones tradicionales y supone un cuestionamiento críticoconstructivo que induce a una reflexión general. Solo entonces es posible entender que lo que se considera "normal" no es sino el resultado de la influencia de un 
determinado pensamiento que se reproduce y perpetúa en todos los ámbitos, incluida la ciencia. A partir de esta reflexión, el cambio es posible.

Entre los retos que en los próximos años debe de afrontar la paleontología se encuentra llevar a cabo una práctica profesional libre de obstáculos sexistas e incorporar la perspectiva de género a sus estudios como un criterio más en la metodología, interpretación y evaluación de sus resultados, de modo que permita evitar los sesgos o evidenciarlos para corregirlos o eliminarlos. Esta otra mirada debería de ser uno de los ejes sobre los que cimentar otra manera de generar y divulgar el conocimiento paleontológico. El objetivo no es hacer una paleontología femenina o en femenino, sino una ciencia mejor, más objetiva y libre de sesgos, lo que inevitablemente lleva hacia una ciencia más inclusiva en todos los sentidos.

\section{AGRADECIMIENTOS}

Queremos agradecer a los tres revisores anónimos sus valiosos comentarios y sugerencias, así como a Esperanza Fernández-Martínez sus siempre constructivas observaciones. Nuestro agradecimiento, igualmente, a Jesús Alvarado Ortega (Instituto de Geología-UNAM), a María Rodríguez-Shadow (DEAS-INAH; CEAM) y a Silvia $\mathrm{M}^{\mathrm{a}}$ Méndez Maín (IIHS-UV) por sus lecturas críticas, y a otros colegas que desde diversos ámbitos aportaron su valioso punto de vista. Todas estas personas han ayudado a mejorar la versión final de este artículo.

\section{REFERENCIAS}

Adams, C. 1990. The Sexual Politics of Meat: a Feminist Vegetarian Critical Theory. New York, Continuum International Publishing Group.

Adovasio, J.M., Soffer, O. \& Page, J. 2007. The Invisible Sex. Uncovering the True Roles of Women in Prehistory. New York, Smithsonian Books/Harper Collins.

Ah-King, M. \& Ahnesjö, I. 2013. The "sex role" concept: an overview and evaluation. Evolutionary Biology, 40, 461-470; doi: 10.1007/s11692-013-9226-7.

Aldrich, M. 1982. Women in Paleontology in the United States 1840-1960. Earth Sciences History, 1, 14-22; doi: 10.17704/eshi.1.1.18226u21t535x768.

Amundsen, T. 2000. Why are female birds ornamented? Trends in Ecolology \& Evolution, 15, 149-155; doi: 10.1016/S0169-5347(99)01800-5.

Anónimo, 1910. The Tyrannosaurus. The American Museum Journal, 10, 3-8.

Ardrey, R. 1976. The Hunting Hypothesis: a Personal Conclusion Concerning the Evolutionary Nature of Man. New York, Atheneum.
Argelés, T., Piqué, R. \& Vilà, A. 1991. La importancia de llamarse hombre en Prehistoria. Revista de Arqueología, $121,6-9$.

Ashby, J. 2017. Animal Kingdom: a Natural History in 100 Objects. Stroud, Gloucestershire, The History Press.

Ballart, J. 2007. Manual de Museos. Madrid, Editorial Síntesis.

Barros del Río, M.A., Bermúdez de Castro, J.M., MorenoTorres, Ch. \& Rios, J. 2015. Evolución en Clave de Género. Burgos, CENIEH.

Bate, L.F. 1998. El Proceso de Investigación en Arqueología. Barcelona, Crítica.

Berihuete, M. \& Piqué, R. 2006. Semillas, frutas, leña, madera: el consumo de plantas entre las sociedades cazadoras recolectoras. RAMPAS, 8, 35-51.

Bernárdez, A. 2015. Mujeres en Medio(s). Propuestas para Analizar la Comunicación Masiva con Perspectiva de Género. Madrid, Editorial Fundamentos.

Binford, L.R. 1981. Bones: Ancient Men, Modern Myths. New York, Academic Press.

Birke, L. 1994. Feminism, Animals and Science: the Naming of the Shrew. Buckingham, Open University Press.

Blumenschine, R.J. \& Cavallo, J.A. 1992. Scavenging and human evolution. Scientific American, 267, 90-97; doi: 10.1038/scientificamerican1092-90.

Boucot, A.J. 1990. Evolutionary Paleobiology of Behavior and Coevolution. New York, Elsevier.

Brochu, C.A. \& Ketcham, R.A. 2003. Osteology of Tyrannosaurus rex: insights from a nearly complete skeleton and high-resolution computed tomographic analysis of the skull. Journal of Vertebrate Paleontology, 22, 1-138; doi: 10.1080/02724634.2003.10010947.

Brusatte, S.L. 2012. Dinosaur Paleobiology, Vol. 2. Hoboken, Wiley-Blackwell.

Brusca, R.C. \& Brusca, G.J. 2005. Invertebrados. Madrid. McGraw-Hill Interamericana de España S.L.

Carlson, S.J. 2013. Paleontologist Barbie. Priscum, 20, 4-5.

Carpenter, K. 1990. Variation in Tyrannosaurus rex. In: Dinosaur Systematics: Approaches and Perspectives (eds. Carpenter, K. \& Currie, Ph.J.). Cambridge, Cambridge University Press, 141-145.

Carpenter, K. 1997. Agonistic behavior in pachycephalosaurs (Ornithischia, Dinosauria); a new look at head-butting behavior. Contributions to Geology, 32, 19-25.

Chapman, R.E., Weishampel, D.B., Hunt, G. \& RaskinnGutman, D. 1997. Sexual dimorphism in dinosaurs. In: Dinofest International: Proceedings of a Symposium Sponsored by Arizona State University (eds. Wolberg, D.L., Stump, E. \& Rosenberg, G.D.). Philadelphia, Academy of Natural Sciences, 83-93.

Childe, G. 1936. Los Orígenes de la Civilización. Fondo Cultural Económica, México.

Clutton-Brock, T.H. 1991. The Evolution of Parental Care. Princeton, Princeton University Press.

Clutton-Brock, T. 2007. Sexual selection in males and females. Science, 318, 1882-1885; doi: 10.1126/ science. 1133311 . 
Clutton-Brock, T. 2009. Sexual selection in females. Animal Behaviour, 77, 3-11; doi: 10.1016/j.anbehav.2008.08.026.

Cockburn, A. 2006. Prevalence of different modes of parental care in birds. Proceedings Biological Sciences, 273, 1375 1383; doi:10.1098/rspb.2005.3458.

Colbert, E. 1955. Evolution of the Vertebrates. New York, John Wiley \& Sons.

Conkey, M.W. \& Spector, J.D. 1984. Archaeology and the study of gender. In: Advances in Archaeological Method and Theory, vol. 7 (ed. Schiffer, M.B.). New York, Academic Press, 1-38.

Crasnow, S., Wylie, A., Bauchspies, W.K. \& Potter, E. 2018. Feminist perspectives on science. In: The Stanford Encyclopedia of Philosophy (ed. Zalta, E.N.). https://plato. stanford.edu/archives/spr2018/entries/feminist-science.

Cruz Berrocal, M. 2009. Feminismo, teoría y práctica de una arqueología científica. Trabajos de Prehistoria, 66, 25-43.

Dart, R.A. 1953. The predatory transition from ape to man. International Anthropological and Linguistic Review, 1, 201-219.

Darwin, C. 1859. On the Origin of Species by Means of Natural Selection. London, John Murray.

Darwin, C. 1871. The Descent of Man, and Selection in Relation to Sex. Vol. II. London, John Murray.

de Terra, H., Romero, J. \& Stewart, T. (eds.) 1949. The Tepexpan Man. Viking Fund Publications in Anthropology, 11. New York, The Viking Fund, Inc.

Dodson, P. 1976. Quantitative aspects of relative growth and sexual dimorphism in Protoceratops. Journal of Paleontology, 50, 929-940.

Emling, S. 2009. The Fossil Hunter: Dinosaurs, Evolution, and the Woman whose Discoveries Changed the World. New York, Palgrave Macmillan.

Fairbairn, D.J., Blanckenhorn, W.U. \& Székely, T. (eds.) 2007. Sex, Size and Gender Roles. New York, Oxford University Press.

Fastovsky, D.E. 2009. Ideas in dinosaur paleontology: resonating to social and political context. In: The Paleobiological Revolution: Essays on the Growth of Modern Paleontology (eds. Sepkoski, D. \& Ruse, M.). Chicago, University of Chicago Press, 239-253.

Fastovsky, D.E. \& Weishampel, D.B. 2009. Dinosaurs. A Concise Natural History. Cambridge, Cambridge University Press.

Flanagan, S.P., Johnson, J.B., Rose, E. \& Jones, A.G. 2014. Sexual selection on female ornaments in the sex-rolereversed Gulf pipefish (Syngnathus scovelli). Journal of Evolutionary Biology, 27, 2457-2467; doi: 10.1111/ jeb. 12487.

Galton, P. 1971. A primitive dome-headed dinosaur (Ornithischia: Pachycephalosauridae) from the Lower Cretaceous of England and the function of the dome of pachicephalosaurids. Journal of Paleontology, 45, 40-47.

Gamble, S. (ed.) 2004. The Routledge Companion to Feminism and Postfeminism. Routledge, New York.

Gándara, M. 2018. De la interpretación temática a la divulgación significativa del patrimonio arqueológico. In: Interpretación del Patrimonio Cultural. Pasos hacia una
Divulgación Significativa en México (coord. Gándara, M. \& Jiménez, M.A.). México, Instituto Nacional de Antropología e Historia, 29-96.

Genovés, S. 1960. Revaluation of age, stature and sex of the Tepexpan remains. Journal of Physical Anthropology, 18, 205-217; doi: 10.1002/ajpa.1330180308.

Gifford-Gonzalez, D. 1993. You can hide, but you can't run: representations of women's work in illustrations of Palaeolithic life. Society for Visual Anthropology Newsletter, 9, 22-41; doi: 10.1525/var.1993.9.1.22.

Gilbert, S.F., Loredo, G.A., Brukman, A. \& Burke, A.C. 2001. Morphogenesis of the turtle shell: the development of a novel structure in tetrapod evolution. Embryology and Development, 3, 47-58; doi: 10.1046/j.1525142x.2001.003002047.x.

Gómez, A. 2006. Introducción. Los estudios de ciencia, tecnología y género. Clepsydra, 5, 11-17.

Goodwin, M.B. \& Horner, J.R. 2004. Cranial histology of pachycephalosaurs (Ornithischia: Marginocephalia) reveals transitory structures inconsistent with headbutting behavior. Paleobiology, 30, 253-267; doi: 10.1666/0094-8373(2004)030<0253:CHOPOM>2.0. $\mathrm{CO} ; 2$.

Goodwin, M.B. \& Evans, D.C. 2016. The early expression of squamosal horns and parietal ornamentation confirmed by new end-stage juvenile Pachycephalosaurus fossils from the Upper Cretaceous Hell Creek Formation, Montana. Journal of Vertebrate Paleontology, 36, e1078343; doi:1 0.1080/02724634.2016.1078343.

Hager, L.D. 1997a. Sex and Gender in Paleoanthropology. In: Women in Human Evolution (ed. Hager, L.D.). London, Routledge, 1-28.

Hager, L.D. (ed.) 1997b. Women in Human Evolution. London, Routledge.

Haraway, D. 1988. Situated knowledges: the science question in feminism and the privilege of partial perspective. Feminist studies, 14, 575-599; doi: 10.2307/3178066.

Harding, S.G. 1986. The Science Question in Feminism. Ithaca, Cornell University Press.

Henry, A. 2012. Chapter 6: Waves. In: Rethinking Women's and Gender Studies (eds. Orr, C.M., Braithwaite, A. \& Lichtenstein, D.). New York, Routledge, 102-118.

Horner, J.R. 1982. Evidence of colonial nesting and 'site fidelity' among ornithischian dinosaurs. Nature, 297, 675676; doi: 10.1038/297675a0.

Horner, J.R. 2012. Dinosaur behaviour. eLS (Encyclopedia of Life Sciences). Chichester, John Wiley \& Sons, Ltd.; doi: 10.1002/9780470015902.a0003318.pub3.

Horner, J.R. \& Goodwin, M.B. 2009. Extreme cranial ontogeny in the Upper Cretaceous dinosaur Pachycephalosaurus. PLoS ONE, 4, e7626; doi: 10.1371/journal.pone.0007626.

Horner, J.R. \& Makela, R. 1979. Nest of juveniles provides evidence of family structure among dinosaurs. Nature, 282, 296-298; doi: 10.1038/282296a0.

ICOM. 2013. Resoluciones aprobadas por la $28^{a}$ Asamblea General del ICOM, Río de Janeiro (2013). https:// icom.museum/wp-content/uploads/2018/07/ICOMsResolutions_2013_Esp.pdf. 
Instituto Nacional de Tecnologías Educativas y de Formación del Profesorado. KAIROS. Programa de apoyo al profesorado de Historia de Secundaria y Bachillerato. Ministerio de Educación, Cultura y Deporte, Gobierno de España. http://recursostic.educacion.es/kairos/web/ ensenanzas/eso/antigua/prehistoria_00.html.

Isaac, G. 1978. The food-sharing behavior of protohuman hominids. Scientific American, 238, 90-108; doi: 10.1038/ scientificamerican0478-90.

Isles, T.E. 2009. The socio-sexual behaviour of extant archosaurs: implications for understanding dinosaur behaviour. Historical Biology: An International Journal of Paleobiology, 21, 139-214; doi: 10.1080/08912960903450505.

Jehl, J.R., Jr. \& Murray, B.G., Jr. 1986. The evolution of normal and reverse sexual size dimorphism in shorebirds and other birds. In: Current Ornithology. Vol. 3 (ed. Johnston, R.F.). New York, Plenum Press, 1-86.

Kent, S. 1998. Gender in African Prehistory. Walnut Creek, CA, AltaMira Press.

Knell, R.J. \& Sampson, S. 2011. Bizarre structures in dinosaurs: species recognition or sexual selection? A response to Padian and Horner. Journal of Zoology, 283, 18-22; doi: 10.1111/j.1469-7998.2010.00758.x.

Krantz, G.S. 1968. Brain size and hunting ability in earliest man. Current Anthropology, 9, 450-451; doi: 10.1086/200927.

Kuhn, S.L. \& Stiner, M.C. 2006. What's a mother to do? A hypothesis about the division of labor and modern human origins. Current Anthropology, 47, 953-981; doi: 10.1086/507197.

Larson, P.L. 1994. Tyrannosaurus sex. In: Dino Fest, the Paleontological Society Special Publication 7 (eds. Rosenberg, G.D. \& Wolberg, D.L.). Knoxvillle, University of Tennessee Press, 139-155.

Larson, P.L. 2008. Variation and sexual dimorphism in Tyrannosaurus rex. In: Tyrannosaurus rex, the Tyrant King (eds. Larson, P.L. \& Carpenter, K.). Bloomington, Indiana University Press, 103-128.

Larson, P.L. \& Frey, E. 1992. Sexual dimorphism in the abundant Upper Cretaceous theropod, Tyrannosaurus rex. Journal of Vertebrate Paleontology, 12 (Sup 3), 38a.

Lee, R.B. \& Devore, I. (eds.) 1968. Man the Hunter. Chicago, Aldine.

Liebowitz, L. 1986. Origins of the sexual division of labor. In: Woman's Nature: Rationalization of Inequality (eds. Lowe, M. \& Hubbard, R.). New York, Pergamon Press, 123-147.

Lorenzo, J.L. 1989. Fechamiento de la mujer de Tepexpan. Boletin del INAH, 28, 2-15.

Love, H.J. \& Sulikowski, D. 2018. Of meat and men: sex differences in implicit and explicit attitudes toward meat. Frontiers in Psychology, 9:559; doi: 10.3389/ fpsyg.2018.00559.

Lovejoy, C.O. 1981. The origin of man. Science, 211, 341-350; doi: 10.1126/science.211.4480.341.

Lyson, T.R., Bever, G.S., Scheyer, T.M., Hsiang, A.Y. \& Gauthier, J.A. 2013. Evolutionary origin of the turtle shell. Current Biology, 23, 1113-1119; doi: 10.1016/j. cub.2013.05.003.
Lyson, T.R., Rubidge, B.S., Scheyer, T.M., de Queiroz, K., Schachner, E.R., Smith, R.M.H., Botha-Brink, J. \& Bever, G.S. 2016. Fossorial origin of the turtle shell. Current Biology, 26, 1887-1894; doi: 10.1016/j.cub.2016.05.020.

Machin, R. 2008. Gender representation in the natural history galleries at the Manchester Museum. Museum and Society, 6, 54-67.

Maiorino, L., Farke, A.A., Kotsakis, T. \& Piras, P. 2015. Males resemble females: re-evaluating sexual dimorphism in Protoceratops andrewsi (Neoceratopsia, Protoceratopsidae). PLoS ONE, 10, e0126464. Doi: 10.1371/journal.pone. 0126464 .

Mallon, J. 2017. Recognizing sexual dimorphism in the fossil record: Lessons from nonavian dinosaurs. Paleobiology, 43, 495-507; doi: 10.1017/pab.2016.51.

Maryanska, T., Chapman, R.E. \& Weishampel, D.B. 2004. Pachycephalosauria. In The Dinosauria, $2^{\mathrm{a}}$ ed. (eds. Weishampel, D., Osmolska, H. \& Dodson, P.). Berkeley, University of California Press, 464-477.

Martínez Pulido, C. 2003. El nuevo enfoque de la evolución sobre la mujer: ¿otra insurgencia científica? Clepsydra, 2, 103-118.

Martínez Pulido, C. 2006. Una perspectiva femenina del pensamiento evolutivo. Clepsydra, 5, 87-94.

Martínez Pulido, C. 2012. La Senda Mutilada: la Evolución Humana en Femenino. Madrid, Minerva.

Molnar, R.E. 1977. Analogies in the evolution of combat and display structures in ornithopods and ungulates. Evolutionary Theory, 3, 165-190.

Molnar, R.E. 2005. Sexual selection and sexual dimorphism in theropods. In: The Carnivorous Dinosaurs (ed. Carpenter, K.). Bloomington, Indiana University Press, 284-312.

Murray, R.L., Wheeler, J., Gwynne, D.T. \& Bussière, L.F. 2018. Sexual selection on multiple female ornaments in dance flies. Proceedings of the Royal Society B: Biological Sciences, 285, 20181525; doi: 10.1098/rspb.2018.1525.

Noble, B. 2016. Articulating Dinosaurs: a Political Anthropology. Toronto, University of Toronto Press.

Okruhlik, K. 1994. Gender and the Biological Sciences. Canadian Journal of Philosophy, 24, 21-42; doi: 10.1080/00455091.1994.10717393.

Osborn, H. 1905. Tyrannosaurus and other Cretaceous carnivorous dinosaurs. Bulletin of the American Museum of Natural History, 21, 259-265.

Osborn, H. 1906. Tyrannosaurus, Upper Cretaceous carnivorous dinosaur. Bulletin of the American Museum of Natural History, 22, 281-296.

Padian, K. 2013. Correcting some common misrepresentations of evolution in textbooks and the media. Evolution: Education and Outreach, 6, 1-13; doi: 10.1186/19366434-6-11.

Padian, K. \& Horner, J.R. 2011. The evolution of 'bizarre structures' in dinosaurs: biomechanics, sexual selection, social selection or species recognition? Journal of Zoology, 283, 3-17; doi: 10.1111/j.1469-7998.2010.00719.x.

Peterson, J.E., Dischler, C. \& Longrich, N.R. 2013. Distributions of cranial pathologies provide evidence for head-butting 
in dome-headed dinosaurs (Pachycephalosauridae). PLoS ONE 8, e68620; doi: 10.1371/journal.pone.0068620.

Plavcan, J.M. 2001. Sexual dimorphism in primate evolution. American Journal of Physical Anthropology, 116, 25-53; doi:10.1002/ajpa.10011.

Plotnick, R.E., Stigall, A.L. \& Stefanescu, I. 2014. Evolution of paleontology: Long-term gender trends in an earthscience discipline. GSA TODAY, 24, 44-45; doi: 10.1130/ GSATG219GW.1.

Preucel, R.W. \& Hodder, I. 1996. Understanding sex and gender. In: Contemporary Archaeology in Theory: a Reader (eds. Preucel, R.W. \& Hodder, I.). Oxford, Blackwell, 415-430.

Ralls, K. 1976. Mammals in which females are larger than males. The Quarterly Review of Biology, 51, 245-276.

Raath, M.A. 1990. Morphological variation in small theropods. In: Dinosaur Systematics (eds. Carpenter, K. \& Currie, P.). Cambridge, Cambridge University Press, 91-105.

Raup, D.M. \& Stanley, S.M. 1971. Principles of Paleontology. San Francisco, W. H. Freeman \& Co.

Rigby, J.K., Jr., Rice, A. \& Currie. P.J. 1987. Dinosaur thermoregulatory Cretaceous/Tertiary survival strategies. Geological Society of America Abstracts with Programs, 19, 820.

Rosvall, K.A. 2011. Intrasexual competition in females: evidence for sexual selection? Behavioral Ecology, 22, 1131-1140; doi: 10.1093/beheco/arr106.

Saitta, E.T. 2015. Evidence for sexual dimorphism in the plated dinosaur Stegosaurus mjosi (Ornithischia, Stegosauria) from the Morrison Formation (Upper Jurassic) of Western USA. PLoS ONE, 10, e0123503; doi: 10.1371/ journal. pone. 0123503 .

Schoch, R.R. \& Sues, H-D. 2015. A Middle Triassic stemturtle and the evolution of the turtle body plan. Nature, 523, 584-587; doi: 10.1038/nature14472.

Schweitzer, M.H., Wittmeyer, J.L. \& Horner, J.R. 2005. Gender-specific reproductive tissue in ratites and Tyrannosaurus rex. Science, 308, 1456-1460; doi: 10.1126/ science. 1112158 .

Schweitzer, M.H., Wittmeyer, J.L. \& Horner, J.R, 2008. One pretty amazing T. rex. In: Tyrannosaurus rex, the Tyrant King (eds. Larson, P.L. \& Carpenter, K.). Bloomington, Indiana University Press, 93-102.

Schweitzer, M.H., Zheng, W., Zanno, L., Werning, S. \& Sugitama, T. 2016. Chemistry supports the identification of gender-specific reproductive tissue in Tyrannosaurus rex. Science Reports, 6, 23099; doi: 10.1038/srep23099.

Shipman, P. 1986. Scavenging or hunting in early hominids: theoretical frameworks and tests. American Anthropologist, 88, 27-43; doi: 10.1525/aa.1986.88.1.02a00020.

Slocum, S. 1975. Woman the gatherer: male bias in Anthropology. In: Toward an Anthropology of Women (ed. Reiter, R.R.). New York, Monthly Review, 36-50.

Snively. E. \& Theodor, J.M. 2011. Common functional correlates of head-strike behavior in the pachycephalosaur Stegoceras validum (Ornithischia, Dinosauria) and combative artiodactyls. PLOS ONE, 6, e21422; doi:10.1371/ journal.pone.0021422.
Spiegel, A.N., Evans, E.M., Frazier, B., Hazel, A., Tare, M., Gram, W. \& Diamond, J. 2012. Changing museum wisitors' conceptions of evolution. Evolution: Education and Outreach, 5, 43-61; doi: 10.1007/s12052-012-0399-9.

Stanford, C.B. 1999. The Hunting Apes: Meat Eating and the Origins of Human Behavior. New Jersey, Princeton University Press.

Stigall, A.L. 2013a. Women in paleontology: where are they? Priscum, 20, 1-3.

Stigall, A.L. 2013b. The Paleontological Society 2013: a snapshot in time. Priscum, 20, 1-4.

Stigall, A.L. 2017. Alumni symposium: women in geology. Post on Stigall Lab blog. http://www.alyciastigall.org/2017/04/ alumni-symposium-women-in-geology.

Sues, H.D. 1978. Functional morphology of the dome in pachycephalosaurid dinosaurs. Neues Jahrbuch für Geologie und Paläontologie, Monatshefte, 8, 459-472.

Sullivan, R.M. 2006. A taxonomic review of the Pachycephalosauridae (Dinosauria: Ornithischia). In: Late Cretaceous Vertebrates from the Western Interior (eds. Lucas, S.G. \& Sullivan, R.M.). Albuquerque, New Mexico Museum of Natural History and Science Bulletin, 35, 347-366.

Tanner, N. \& Zihlman, A. 1976. Women in evolution. Part I: innovation and selection in human origins. Signs, 1, 585608; doi: 10.1086/493245.

Torrens, H. 1995. Presidential address: Mary Anning (17991847) of Lyme; 'the greatest fossilist the world ever knew'. The British Journal for the History of Science, 28, 257-284; doi: 10.1017/S0007087400033161.

Varricchio, D.J., Moore, J.R., Erickson, G.M., Norell, M.A., Jackson, F.D. \& Borkowski, J.J. 2008. Avian paternal care had dinosaur origin. Science, 322, 1826-1828; doi: 10.1126/science. 1163245 .

Washburn, S.L. \& Devore, I. 1961. Social behaviour of baboons and early man. In: Social Life of Early Man (ed. Washburn, S.L.). Chicago, Aldine-Atherton, 91-105.

Weedman, K. 2010. Feminine knowledge and skill reconsidered: women and flaked stone tools. American Anthropologist, 112, 228-243; doi:10.1111/j.15481433.2010.01222.x.

Wheeler, P. \& Greenwood, P.J. 1983. The evolution of reversed sexual dimorphism in birds of prey. Oikos, 40, 145-149.

Wylie, A. 1997. The engendering of archaeology refiguring feminist science studies. Osiris, 12, 80-99; doi: 10.1086/649268.

Zihlman, A. 1978. Women in evolution, part II: subsistence and social organization among early hominids. Signs, 4, 4-20; doi: 10.1086/493245.

Zihlman, A. 1997. The Paleolithic glass ceiling: women in human evolution. In: Women in Human Evolution (ed. Hager, L.D.). London, Routledge, 91113.

Zihlman, A. 2012. The real females of human evolution. Evolutionary Anthropology: Issues, News, and Reviews, 21, 270-276; doi: 10.1002/evan.21331. 
